Ulloa, T. (2020). La reinterpretación de los parámetros espaciales. Sus formas de expresión en muestras orales de hablantes de la ciudad Santiago de Cuba. RILEX. Revista sobre investigaciones léxicas, 3/I, pp. 96-108.

\title{
LA REINTERPRETACIÓN DE LOS PARÁMETROS ESPACIALES. SUS FORMAS DE EXPRESIÓN EN MUESTRAS ORALES DE HABLANTES DE LA CIUDAD DE SANTIAGO DE CUBA.
}

\section{REINTERPRETATION OF SPATIAL PARAMETERS. HIS FORMS OF EXPRESSION IN ORAL SAMPLES OF SPEAKERS OF THE CITY OF SANTIAGO DE CUBA}

\author{
Tania Ulloa \\ Universidad de Oriente \\ tania@uo.edu.cu
}

\begin{abstract}
RESUMEN
Las representaciones lingüísticas de las relaciones espaciales, debido al carácter móvil del hombre y a la comprensión material del mundo en el que este habita (objetos, formas y superficies) están presentes en todas las lenguas del mundo; sin embargo, diversos estudios consultados apuntan que los hablantes describen y organizan estas relaciones de modos distintos. El presente trabajo permite mostrar que el comportamiento discursivo de la deixis espacial es de interés, tanto desde el punto de vista de la teoría gramatical como desde la óptica de su comportamiento discursivo, pues se corresponden con formas lingüísticas que adquieren plenitud referencial dentro del contexto pragmático en que son utilizadas.
\end{abstract}

Palabras clave: deixis espacial, comportamiento discursivo, pragmática, discurso oral

\begin{abstract}
The linguistic representations of spatial relations, due to the mobile character of man and the material understanding of the world in which he inhabits (objects, forms and surfaces) are present in all the languages of the world; however, several studies consulted indicate that speakers describe and organize these relationships in different ways. The present work allows us to show that the discursive behavior of the spatial deixis is of our interest, both from the point of view of grammatical theory and from the point of view of its discursive behavior, since they correspond with linguistic forms that acquire referential plenitude within the pragmatic context in which they are used.
\end{abstract}

Keywords: Keywords: spatial deixis, discursive behavior, pragmatic, oral discourse. 


\section{INTRODUCCIÓN}

La articulación del espacio lingüística difiere considerablemente de lo que se conoce como configuraciones del espacio métrico. Las propiedades espaciales atribuidas a las cosas, sus dimensiones, sus posiciones y sus movimientos, proceden de una experiencia del mundo en la que los hombres son sujetos y actores; es por ello que no es solo materia de estudio de la física y la geometría, sino también de la psicología, la antropología y la lingüística. El espacio deíctico, como muchos autores han descrito, es nuestra representación mental del espacio físico estructurado por la percepción visual, por nuestro conocimiento geográfico o por otros aspectos del conocimiento de su estructura (Cifuentes, 1989, p. 254).

El espacio de la percepción (entendido también como conceptualización), es con el que opera el espacio lingüístico. Es un espacio relacional y funcional, en el que ocupa un lugar fundamental, junto al juego de coordenadas y dimensiones, la posible interacción - conceptual o cultural- establecida entre los distintos objetos que se pretendan localizar o entre esos objetos y el enunciador. Las señalizaciones, sin duda, no están dadas en abstracto métricamente, sino que son dependientes del tipo de relaciones que se establecen entre los elementos y fundamentalmente del sujeto enunciador, cuya perspectiva e interacción marcará la clave de interpretación y comprensión de la espacialización elegida, según apunta Cifuentes Honrubia (1989, p. 243).

Las relaciones espaciales, por otro lado, han sido consideradas como básicas en la conceptualización de la experiencia y organización semántica de las lenguas, pues cada conglomerado social organiza su territorio según una espacialidad que le es propia. La deixis espacial o local señala los elementos de lugar en relación con el espacio que crea el yo como sujeto de la enunciación; es por ello que sus límites son muy subjetivos, ya que dependen, además, de la subjetividad del hablante y la de su interlocutor. Estas expresiones poseen la compleja función de transferir los datos del espacio tridimensional al formato unidimensional del lenguaje.

Una primera distinción básica entre las unidades deícticas se relaciona con el tipo de información deíctica. Desde este punto de vista, la deixis espacial codifica las referencias locativas de los enunciados en relación con la situación y orientación física de los participantes en el acto de habla (Escavy, 2009, p. 70). 
Desempeñan esta función, en la lengua española, los pronombres demostrativos, los adverbios demostrativos de lugar, los verbos deícticos y otras expresiones con significado deíctico-espacial, entre ellas, adverbios nominales transitivos e intransitivos, determinadas frases preposicionales locativas y algunos sustantivos y adjetivos.

Los pronombres demostrativos constituyen un paradigma ternario cerrado - este, ese aquelque manifiesta una variación genérica triple - masculino, femenino y neutro-y numérica doble - singular y plural-. Son los encargados de situar en las coordenadas espaciales las entidades referidas por los sustantivos a los que determinan o sustituyen (Hipogrosso, 2003, s.p.); se convierten en índices que indican el objeto desde el punto de origen del hablante, por lo que desarrollan una dimensión deíctica espacial articulada sobre la dimensión personal, constituyendo, de esta forma, los representantes más característicos del paradigma de las categorías deícticas.

La flexibilidad de este sistema permite la aparición de una gama compleja de usos, específicamente en la lengua coloquial, en los cuales deben reinterpretarse las dimensiones espaciales antes descritas. Por ejemplo, el empleo de este con valor afectivo; de ese en señal de distanciamiento o con matiz despectivo; de aquel para evocar lejanía en el tiempo; el uso de muletillas esteeee...estooooo como señal de duda o indecisión; de fórmulas fijas eso sí que no, eso nunca, de eso nada, en esas estamos, con que esas tenemos; el empleo de y eso que, con valor concesivo y de en eso, con significado de entonces.

Este sistema manifiesta, por otro lado, un evidente paralelismo con los adverbios demostrativos de lugar pues ambos establecen tres grados de distancia en relación con el centro deíctico.

Los adverbios demostrativos de lugar en la lengua española constituyen un reducido grupo de unidades lingüísticas (aquí, ahi, allí, acá, allâ) morfológicamente invariables cuya función más habitual es la de complemento circunstancial o adjunto de un verbo (Eguren, 2000, p. 955). Esta clase de adverbios ha sido etiquetada de maneras distintas (pronominales o deícticos) resaltando, en cada caso, diversos aspectos de su semántica o sintaxis.

Su interpretación depende del lugar en que se encuentre el hablante, por lo que se relaciona con el centro deíctico de la enunciación; de esta forma, los adverbios demostrativos refieren al espacio de manera deíctica. Se organizan en dos subsistemas, uno ternario (aquí, abi, alli) y otro 
binario (acá, allâ). El primero manifiesta un evidente paralelismo con el sistema de pronombres demostrativos (este, aquí, ese, abí, aquel, alli) y como estos, establece tres grados de distancia. El otro postula una relación binaria (acá, allâ) y expresa proximidad o lejanía relativas con respecto al lugar en el que se encuentra el hablante.

Estas unidades, al identificar el espacio deíctico, establecen, por otro lado, cierta flexibilidad en los grados de distancia que señalan con respecto al centro deíctico; en algunos casos, pueden adoptar un valor temporal allá en los tiempos de, desde entonces hasta acá, de aqui en adelante; pueden ser usadas para referirse a alguien que se encuentra cerca del hablante acá tiene la razón; expresar un uso enfático despáchame una caja de fósforos abí y, en otros casos, restan importancia a una determinada información es una casucha ahi. En el registro coloquial abi quería llegar, abí voy se emplean para resaltar la pertinencia de lo que acaba de decir alguien; dime abíse usa para enfatizar una petición; abi estamos o ahi más o menos son fórmulas que responden a las preguntas corteses que caracterizan los saludos.

La denominación de verbos deícticos, por otro lado, se basa en la oposición esencial entre posición estática (reposo) y dinámica (movimiento). Cifuentes Honrubia (1989, p. 59) observa que su conceptualización no es sino una categorización de las relaciones físicas en términos gramaticales. La localización se fundamenta en la ubicación espacial de los participantes del acto comunicativo mientras el movimiento describe una trayectoria poniendo en relación un punto de observación también vinculado con esa propia posición.

Los verbos de movimiento en español son, por otro lado, fuente de numerosos marcadores discursivos o conversacionales como: venga, anda, vaya, vamos; en otros casos, expresiones como llegar a oídos de alguien, entrar en éxtasis, entrar en calor, salirse de sus casillas pueden describir un movimiento en sentido figurado o admitir, en contextos distintos, usos tanto espaciales como atributivos: Pedro se encuentra en Berlín / Pedro se encuentra en apuros.

Estas representaciones lingüísticas de las relaciones espaciales, debido al carácter móvil del hombre y a la comprensión material del mundo en el que este habita (objetos, formas y superficies) están presentes en todas las lenguas del mundo; sin embargo, diversos estudios consultados apuntan que los hablantes describen y organizan estas relaciones de modos distintos pues difieren en su estructuración sistemática, así como en el número y tipo de categorías lingüísticas que las señalan. 
El estudio de la deixis permite distinguir cómo se inscriben en los enunciados los parámetros referentes al contexto enunciativo, los cuales dan cuenta de la existencia de principios generales en el uso del lenguaje, pues justamente son los deícticos quienes más claramente expresan el principio de determinación contextual de la significación; por consiguiente, se hace necesario, para el análisis de los locativos espaciales, una lectura pragmática que considere las condiciones que determinan tanto el empleo de un enunciado por un hablante en una situación comunicativa concreta como su interpretación por parte del destinatario.

El presente estudio permite dirigir la atención hacia el hecho de que toda expresión deíctica empleada lleva implícita, además, una intencionalidad del sujeto, lo que equivale a reconocer que la construcción del significado no solo está ligada al establecimiento de las coordenadas espacio-temporales de la enunciación.

\section{LA MUES'TRA}

Uno de los componentes básicos de las investigaciones de carácter lingüístico son los hablantes, pues son ellos los que aportan los materiales que integran el repertorio de datos. Considerando lo anterior, se tuvo en cuenta para su selección que las personas fueran oriundas de la ciudad de Santiago de Cuba; de no ser así debían tener más de veinte años de residencia permanente en la misma. Con el propósito de obtener una muestra heterogénea fueron incluidos informantes con niveles de instrucción variados, que pertenecieran a grupos etarios diferentes y de distintos sexos.

La muestra se compone de treinta grabaciones auditivas, correspondiente a igual número de informantes, con una duración aproximada de quince minutos cada una. Una vez recogida toda la información y luego de su transcripción, la cual constituye una parte fundamental del análisis ya que implica la primera manipulación de los datos obtenidos, se extrajeron las expresiones deícticas objeto de estudio empleadas por los hablantes.

La transcripción grafemática se subordina al objeto y la finalidad del estudio, por tal razón, en esta investigación, se usaron las convenciones gráficas de A. Briz y el Grupo Val.Es.Co (2000).

Novedosa resulta, además, realizar la indagación en la ciudad de Santiago de Cuba, segundo centro poblacional más importante del país y cuyos valores históricos y culturales la convierten en un sitio idóneo para cualquier pesquisa de carácter humanístico y lingüístico en particular. 


\section{ANÁLISIS}

A pesar de que el contexto no está determinado por el emisor, este puede condicionarlo de alguna forma y proyectar una situación que logre ser comprendida de forma satisfactoria por el otro; en este sentido, es el destinatario el que tiene que asumir la contextualización de la emisión lingüística en cuestión, tratando de reconstruir el entorno óptimo para su interpretación; se hace necesario, por un lado, reconocer su papel en la interpretación como un límite al conjunto de posibles interpretaciones y, por otro, como un apoyo para la interpretación pretendida (González, 2007, p. 80).

Desde esta misma perspectiva deben considerarse los usos figurados y metafóricos, los cuales se encuentran motivados por esquemas cognitivos subayacentes en la mente humana que surgen de nuestra experiencia del mundo al trasladarse los valores espaciales primarios a otros más abstractos. En los ejemplos que siguen, la transferencia semántica consiste generalmente en concebir el fenómeno abstracto como el objeto mismo del movimiento, esto es, como un objeto transportable en el espacio. La expresión del movimiento metafórico se construye, como podrá observarse, sobre esquemas sintácticos similares a los utilizados para designar desplazamiento real:

Tú sabes que viene el tifo y el que no se vacune se muere: la personificación sugiere que la enfermedad de la que se comenta está siendo frecuente cerca de la zona en la que se encuentra el hablante.

La carne venía a la pescadería semanalmente, el yogurt no viene todos los días: en este caso, debido a la personificación producida, el objeto que se desplaza adquiere el sema de $(+)$ animado, otorgando entonces a la expresión en su conjunto otro significado (la carne la vendían frecuentemente; el yogurt no lo venden todos los días).

De dónde me vino esa idea: en este ejemplo el verbo denota un movimiento hacia el hablante pero en sentido abstracto adquiriendo, de esta forma, valor reflexivo; es empleado para autentificar sus criterios y reflexiones personales.

En el plano discursivo, como puede apreciarse, existen ocasiones en las que las coordenadas y dimensiones de las nociones de lugar no son codificadas de forma deíctica (las anteriores estructuras con ausencia de los rasgos locativos prototípicos constituyen un ejemplo); la manera en que se configura cada enunciado, por tanto, sirve de guía para su interpretación al 
incorporar otros aspectos entre los que se encuentran, por ejemplo, las intenciones del productor del texto.

En este caso, por ejemplo, resultó interesante el manejo discursivo del verbo (llevar) en la Carabali lleva niños y lleva jóvenes pues en este contexto adopta otro significado que no implica movimiento (la carabalí está integrada por niños y jóvenes). A pesar de que el contexto no está determinado por el emisor, este puede condicionarlo de alguna forma y proyectar una situación que logre ser comprendida de forma satisfactoria por el otro; en este sentido, es el destinatario el que tiene que asumir la contextualización de la emisión lingüística en cuestión, tratando de reconstruir el entorno óptimo para su interpretación.

En el próximo fragmento, sin embargo, es usado por el hablante para indicar permanencia en la región espacial donde se desarrolla la conversación (esta provincia-llevo en ella): Esta provincia claro que me gusta y llevo en ella ya muchos años / te cuento / yo soy de Guantánamo y vine para acá cuando mi bijo tenía diecisiete meses de nacido.

Para el estudio de los locativos espaciales se hace necesario, por tanto, una lectura pragmática que considere las condiciones que determinan tanto el empleo de un enunciado por un hablante en una situación comunicativa concreta como su interpretación por parte del destinatario; los próximos ejemplos así lo evidencian.

La utilización de la forma verbal en uno tiene que adaptarse en la vida a todo / cuando yo entré a la universidad/ aquello fue algo impactante para mi muestra una reinterpretación de las características espaciales objetivas asociadas al parámetro de interioridad (cuando yo entré a la universidad / cuando yo comencé a estudiar en la universidad).

En el siguiente fragmento merece comentarse el empleo del adverbio nominal intransitivo arriba, el cual es usado, en este contexto Podría asi / por arriba decirte algunas cosas», con otro significado (podría así / sin dar detalles / decirte algunas cosas).

En otro caso, el empleo de volver en se le despide el duelo / entonces vuelve la conga adquiere en este contexto otro significado (se le despide el duelo / entonces suena nuevamente la conga); y por otro, el uso de subir en desde el primer momento del toque y están haciendo esas cosas se suben donde refiere cuestiones pertenecientes a la religiosidad popular y no desempeña su papel semántico al expresar relaciones espaciales. 
En los próximos ejemplos el verbo de desplazamiento (llegar), que focaliza la parte final de la trayectoria y su acción culmina al alcanzar la meta, es empleado con otro significado. En el enunciado aqui, esperando que me llegue la hora definitiva, por ejemplo, tiene otro sentido. En este caso, el hablante hace recaer la acción sobre sí mismo en un determinado lapso de tiempo para atenuar la carga semántica (yo estoy aquí esperando la muerte); la acción durativa de la expresión es aportada por el gerundio (yo, aqui, esperando): Yo fui una gente que me cuidé mucho de no cometer errores y mira boy como todo el mundo tiene su casa y todavía no he terminado la mía / por ser bueno y honrado // antes la gente me respetaba / yo voy a las reuniones y todo eso se valora pero ya estoy cansado/ sigo con un salario bajo y aqui esperando que me llegue la hora definitiva.

En el siguiente fragmento indica el punto final de un trayecto (cuando llegué al noveno grado) que se hace corresponder con un determinado lapso de tiempo: Me puso en la escuela de música en la Vasfuentes que es una escuela taller / no tiene mucho prestigio / para mi / fue muy importante en mi vida pero lamentablemente esta escuela no tiene mayor nivel / no está al nivel de otras escuelas de música en el país / cuando llegué al noveno grado no pude continuar / intenté pero Dios tiene el control de todo y él sabe las cosas.

En este último ejemplo el significado de tú llegas a la conclusión implica, en este contexto, un proceso acumulativo que presupone la existencia de una trayectoria recorrida antes de alcanzar la meta (esta rona es la mejor): Tú vas a La Habana / Martí / tú ves aquí / Martí/ en Matanzas te hablan de Martí / hasta en canción se escucha Martí / / asi tú llegas a la conclusión de que esta zona es la mejor.

La presencia de los deícticos, como ha podido mostrarse, es un fenómeno medular del lenguaje, por lo que su estudio resulta en ocasiones complejo; al hablar no solamente se simboliza, sino también se señalan realidades específicas en el mundo extralingüístico, las cuales exigen para su identificación puntos de referencia que se ubiquen dentro de un determinado sistema de mostración. La elección de estas expresiones presupone el conocimiento por parte del hablante de una situación espacio-temporal dada, así como el conocimiento de un sistema lingüístico específico (el sistema de marcadores deícticos de la lengua en uso) cuyos elementos poseen condiciones contextuales muy concretas de utilización, como se aprecian en los próximos ejemplos. 
El uso del verbo meter en el siguiente fragmento, no señala la dimensión interior nadie se metía si tú no ibas al aula, si no bajabas a comer, si salías de la escuela / si no entrabas, sino que es utilizado con otro significado a nadie le interesaba si tú no ibas al aula, si no bajabas a comer. La partícula condicional aporta a la interpretación pues presenta los hechos a partir del cambio de localización constante.

En otro caso el hablante refiere con la expresión los instrumentos se les bajaban, que los tambores, como consecuencia del toque continuado, se pusieron fláccidos; en este ejemplo se observa una localización deíctica inherente; si bien la dimensión vertical suele organizarse universalmente a partir del eje cielo-tierra, en el ejemplo el eje utilizado es el que proporciona la superficie del tambor: Cuando la conga salia tocaba tres cuadras y babia que parar / no porque se cansaban los músicos sino porque los instrumentos se les bajaban y entonces ellos tenían que sacar los periódicos del bolsillo / hacer una candela / una fogata y darles calor para tensarlos y entonces poder seguir tocando.

De igual forma, la situación hipotética observada en el siguiente fragmento permite que la dimensión exterior indicada por el adverbio (un día me quedo fuera) sea interpretada en otro sentido (un día pierdo el trabajo): No es que yo me vaya a dedicar a ser chofer / porque realmente es una opción que tengo / un dia me quedo fuera y quizás me dedique a manejar.

En los tres ejemplos que siguen resultan interesantes algunos usos discursivos de los deícticos analizados; como por ejemplo, la manera de enmarcar un determinado lapso de tiempo a partir del empleo de un verbo deíctico con foco en la meta (viene de lunes a viernes); o en llevé el departamento al primer lugar donde no se produce un movimiento orientado hacia una posición distinta de la ubicación del hablante, pues refiere, en este caso, el empeño personal y la constancia en el trabajo del productor del texto. En el último fragmento, la construcción estativa aqui estoy, cuyo significado básico se relaciona con la coordenada espacial de la enunciación, actúa en ese contexto como respuesta afirmativa ante una posible petición que le antecede (si me llaman):

Lo que bice fue que pedí la baja y me dediqué a estar aqui / todo eso duró desde el 2003 hasta el 2010 que fue que se graduó / / ahora me dedico aquí a los nietos / la niña la tengo en la escuela/ la llevo/la traigo porque ellos viven distantes y la traigo para acá y cuando comience preescolar viene de lunes a viernes. 
Me fui para la escuela del partido / acepté irme para la escuela de economía en Aguadores y llevé el departamento al primer lugar / boy por hoy me encuentro aqui en la casa / jubilado y agradecido de la Revolución.

Asi estuve durante los cinco años hasta que por fin vine para aquí y continú trabajando como enfermera en el policlínico / / abora están evaluando los potenciales de las enfermeras que ya fuimos a Venezuela pues estamos propuestas para ir a Brasily si me llaman / aqui estoy.

Como ha podido mostrarse, son los participantes en la comunicación los que determinan las coordenadas que componen cada acto de enunciación, al convertirlo en un proceso interpersonal y continuo. La articulación en el plano discursivo de los ejes espacial y temporal sobre los que se apoya la referencia de naturaleza deíctica así lo demuestra.

La deixis temporal sitúa lo descrito en el discurso en relación con el momento en que tiene lugar el intercambio. Sus manifestaciones verbales se amplían extraordinariamente en el marco discursivo al permitir el desdoblamiento del emisor y receptor en la selección de las unidades que configuran el discurso, como puede apreciarse en los próximos ejemplos.

En el primer caso se observa un uso no espacial del adverbio abí, el cual adopta en este contexto, un significado temporal (de abi empecé a trabajar - después empecé a trabajar): Todo el mundo no tiene las mismas oportunidades en la vida / yo no tuve la posibilidad de estudiar / te cuento / allá yo estudié hasta el sexto grado / de abi empecé a trabajar / muy joven en ese pueblito donde nacieron mis padres...

El verbo de localización estar es usado en el próximo ejemplo en la expresión cuando estábamos en buenas para referirse, en este caso, a un determinado período de tiempo en el que se produce un movimiento (vino el ciclón Flora) muy relacionado con el objetivo argumental de lo que se cuenta: Yo empecé a trabajar en 1946 / estuvimos luchando y cuando estábamos en buenas vino el ciclón Flora I que devastó la finca de mis padres por completo...

En el último fragmento (eso fue cerca del momento de venir) hace referencia al momento en que tuvo lugar el evento descrito en el relato (uso temporal) a partir del empleo de un demostrativo en función anafórica; el uso de venir, implica, por tanto, la presencia del hablante en la meta del movimiento, pero en el tiempo en que se desarrollan los hechos narrados: Se realizaron varias charlas educativas / dialogamos asi como intercambiamos experiencias sobre el trabajo que se realiza aqui en Cuba / / aparte del trabajo fuimos a lugares de interés recreativo / fuimos a sitios con altos valores históricos así como museos galerías etc. // uno de los lugares más interesantes que visitamos fue el Monte Ávila // para 
ir hacia allá nos trasladamos en un teleférico / / subimos entre las montañas hasta la cima, / allá hay una pista de patinaje sobre bielo / eso fue cerca del momento de venir...

Por otro lado, resulta interesante en el siguiente fragmento, el empleo de la preposición, la cual conceptualiza un recorrido que se focaliza en el punto de destino (para seguir adelante); el adverbio, por su parte, señala una posición que tiene como referencia la existencia de órganos sensoriales concentrados en la parte frontal del cuerpo humano, lo cual permite relacionar la expresión en su conjunto con un trayecto sin retroceso que hace coincidir el hablante con su experiencia personal: En la finca siempre bubo de todo / café y todo tipo de alimentos y así vivimos saliendo a vender lo que se cosechaba para mantenernos y asi he pasado toda mi vida hasta hoy / luchando por mis hijos y haciendo lo que haga falta para seguir adelante...

En el último ejemplo la señalización espacial realizada (la gente está para afuera, en la calle) permite, a partir del empleo de las preposiciones, otorgar a la expresión en su conjunto un significado que apunta hacia lo subjetivo en el marco de las relaciones sociales; (la gente está para afuera) indica primeramente una localización en el espacio exterior que es precisada (la gente está para afuera $=$ en la calle), todo con el objetivo de dar a conocer las características de las personas que habitan el barrio y que han servido de argumento para su relato (son comunicativas, sociables, extrovertidas): Este es un barrio donde la gente está para afuera/ en la calle/ la gente se comunica/ se sirve, es un barrio solidario/ a veces bullero/ a veces complicado pero es un barrio realmente solidario.

\section{CONCLUSIONES}

El análisis realizado ha permitido demostrar que el comportamiento discursivo analizado se caracteriza por la presencia de usos que están determinados por las características del tipo de texto en que se producen y por condicionamientos de orden pragmático y semánticoreferenciales. La indagación científica muestra que estas señalizaciones a la realidad extralingüística son de interés, tanto desde el punto de vista de la teoría gramatical como desde la óptica de su comportamiento discursivo, pues se corresponden con formas lingüísticas que adquieren plenitud referencial dentro del contexto pragmático en que son utilizadas.

La operatividad referencial de estas representaciones deícticas posibilita además, como ha sido mostrado, la aparición de determinados usos figurados y metafóricos; para ello, los deícticos espaciales son situados en contextos pertinentes que permiten dotar de esa 
interpretación significativa estas expresiones lingüísticas a partir de la existencia de una base de conocimientos compartidos entre los hablantes.

El análisis de los deícticos espaciales mostró una gama compleja de empleos, como son: la reinterpretación de las características espaciales objetivas asociadas al parámetro de interioridad, el significado conceptual del movimiento y la extensión del sentido de dirección; estos usos evidenciaron los múltiples valores semánticos que se pueden adquirir en el contexto.

Estudiar estos procesos y su manifestación en el uso, como puede apreciarse, nos aporta información relevante en cuanto a nuestro comportamiento como seres humanos. El hablante organiza su discurso en función de que el oyente pueda utilizarlo como una guía para la construcción de la representación conceptual que se intenta compartir o comunicar. El presente trabajo contribuye, de esta forma, al conocimiento de aspectos que no han sido lo suficientemente abordados por los estudios lingüísticos en la lengua española pues describe el empleo de estas formas lingüísticas en correspondencia con las informaciones que aportan en cada situación de uso.

\section{BIBLIOGRAFÍA}

Amores Sierra, T. (2011). Relacionantes espaciales en el texto. En J. de Santiago Guervós, H. Bongaerts, J. J. Sánchez Iglesias y M. Seseña Gómez (coords.), Del texto a la lengua: La aplicación de los textos a la enseñanzaaprendizaje del español L2-LE. Salamanca: Asociación para la Enseñanza del Español como Lengua Extranjera [en línea] https://dialnet.unirioja.es/servlet/articulo?codigo=5419309 [18/11/2019].

Baquero, S. (2002). Aprendiendo a expresar eventos de movimiento en inglés y coreano. Elementos para su marco conceptual subyacente. Forma y función, 15, pp. 41-59. [en línea] http: www.redalyc.org/articulo.oa?id=21901503 [15/10/2019]

Briz, A (2000). Cómo se comenta un texto coloquial. Madrid: Editorial Ariel.

Bosque, I., y Demonte, V. (dir.) (2000). Gramática descriptiva de la lengua española. Vol.1. Madrid: Espasa Calpe.

Calvo, P. J. (1994). Introducción a la pragmática del español. Madrid: Cátedra.

Castillo, M. V., y Camacho, C. A. (2007). El uso de elementos indexicales en los textos narrativos orales sobre botijas y espiritus en la comunidad de Valle Guanape, Edo. Anzoátegui. Trabajo de grado, Antropología, Universidad Central de Venezuela. CAracas. [en línea] http://saber.ucv.ve/handle/123456789/807 [20/8/2019].

Cifuentes Honrubia, J. L. (1989). Lengua y espacio. Introducción al problema de la deixis en español. Alicante: Universidad de Alicante.

Cifuentes Honrubia, J. L. (1988-1989). Sobre las construcciones locales en español. Estudios de lingüística, 5, pp. 145181. https://doi.org/10.14198/ELUA1988-1989.5.11

Cifuentes Honrubia, J. L. (1999). Sintaxis y semántica del movimiento. Aspectos de gramática cognitiva. Alicante: Instituto de Cultura Juan Gil Albert. 
Escavy Zamora, R. (2009). Pragmática y textualidad. Murcia: Ediciones de la Universidad de Murcia.

Eguren, L. (2000). Pronombres y adverbios demostrativos. Las relaciones deícticas. En I. Bosque y V. Demonte (dir.), Gramática descriptiva de la lengua española. Vol.1. Madrid: Editorial Espasa Calpe, pp. 929-972.

González Navarro, M. (2007). Claves para la actualidad de la hermenéutica (Tesis doctoral). Universidad Complutense de Madrid, Madrid.

Hernández Socas, H. et al (2011). Tiempo, espacio y relaciones espacio-espaciales. Nuevos aportes a los estudios contrastivos. Berlín: Peter Lang.

Hipogrosso, C. (2003). El campo mostrativo del lenguaje: una introducción al comportamiento de los pronombres. Revista de la Educación del pueblo, 89, s.p. [en línea] http://materialeshipo.blogspot.com/2006/12/el-campomostrativo-del-lenguaje.html [3/11/2018]

Lizarralde, C., y Salamanca, G. (2019). Deixis espacial en el rromané jorajané hablado en chile: uso de los demostrativos en espacio de escala menor. Alpha, 49, pp. 274-298. http://dx.doi.org/10.32735/s07182201201900049753

Morimoto, Y. (2001). Los Verbos de movimiento. Madrid: Visor.

Paz Afonso, A. (2014). Semántica cognitiva e historia del léxico: evolución de los verbos entrar y salir (ss. XIII-XV) (Tesis doctoral). Universidad Autónoma de Barcelona. Barcelona.

Palma N., e Ismalí, A. (2003). Sentido figurado y cognición: espacio virtual como espacio contenedor. Onomazein, 8, pp. 261-274.

Real Academia Española (1982). Esbozo de una nueva gramática de la lengua española. 8va reimpresión. Madrid: Espasa Calpe.

Real Academia Española (2009). Nueva gramática de la lengua española. Asociación de academias de la lengua española. España: Espasa Libros.

Rincón Alfonso, E. (2018). La iluminación pragmatista de la deixis (Trabajo de Grado). Pontificia universidad Javeriana. Bogotá. [en línea] https://repository.javeriana.edu.co/bitstream/handle/10554/36899/la\%20iluminaci $\%$ C3\%B3n $\% 20$ prag matista $\% 20$ de $\% 201 \mathrm{a} \% 20$ deixis.pdf?sequence $=1$ \&isAllowed $=\mathrm{y}[14 / 11 / 2019]$.

Silva Corvalán, C. S. (2001). Sociolingüística y Pragmática. Washington DC: Georgetown University Press.

Suadoni, A. (2014). Verbos de movimiento, deixis y proyección metafórica. El caso de andare y venire con ir y venir (Tesis doctoral). Universidad de Granada. Granada. 